\title{
LOS MOVIMIENTOS NACIONAL-POPULARES Y SUS \\ POLÍTICAS PÚBLICAS: NACIONALISMO ANTIOLIGÁRQUICO, DEMOCRATIZACIÓN Y ANTILIBERALISMO
}

\author{
Joaquín Fernández Abara \\ Universidad Finis Terrae, Chile \\ jfernandez@uft.cl
}

\section{RESUMEN}

A través del análisis de bibliografía historiográfica y teórica, principalmente de la sociología y la ciencia política, se analizará la relación de los movimientos nacional populares, en cuanto tipo específico de populismo, con las políticas públicas. Se propondrá el uso del concepto Movimientos Nacional-Populares para tipificar a los movimientos nacionalistas y antioligárquicos que emergieron en América Latina en el segundo tercio del siglo XX y se analizaran sus principales características, centrándose en su carácter democratizante a la vez que antiliberal. Con este fin se propondrá el uso de una definición ideacional mínima de populismo y de una definición acumulativa para los movimientos nacional populares. Se sostendrá que, si bien resulta imposible asociar al populismo a un tipo de política pública específica, esto si puede hacerse en el caso de los movimientos nacional populares, los que promovieron políticas públicas democratizadoras, que apuntaban a la integración social a la vez que mantuvieron un sesgo antiliberal.

Palabras clave: Movimientos nacional-populares, Populismo, Políticas públicas, América Latina. 


\title{
NATIONAL-POPULAR MOVEMENTS AND THEIR PUBLIC POLICIES: ANTI-OLIGARCHY NATIONALISM, DEMOCRATIZATION AND ANTI-LIBERALISM
}

\begin{abstract}
Through the analysis of historiographical and theoretical bibliography, principally from sociology and political science, this paper analyzes the relationship of national-popular movements, understood as a specific type of populism, with public policies. The concept of national-popular movements is used to typify the nationalist anti-oligarchy movements that appeared in Latin America in the second third of the twentieth century and to analyze their main characteristics, focusing on their democratizing as well as anti-liberal nature. For this purpose, the paper proposes the use of a minimum ideational definition of populism and a cumulative definition for national-popular movements. It argues that, although it is impossible to associate populism with a specific type of public policy, this is possible in the case of national-popular movements, which promoted democratizing public policies, aimed at social integration, whilst maintaining an antiliberal bias.
\end{abstract}

Keywords: National-popular movements, Populism, Public policies, Latin America. 


\section{INTRODUCCIÓN}

Uno de los conceptos más controvertidos en las ciencias sociales es el de populismo, esto pues existen diversas interpretaciones sobre su naturaleza, sus características y su génesis. Dicho escenario ha llevado a algunos académicos a poner en duda su utilidad y pertinencia. Considerando importante mantener la utilización del término populismo, pues da cuenta de fenómenos políticos de carácter antielitista y reivindicativos de lo popular, sostenemos la necesidad de utilizar conceptos universalistas y generales para entenderlo. A la vez, planteamos la importancia de generar categorías de análisis específicas, que actúen como teorías de alcance medio, para denominar y comprender a formas históricas y concretas de este. De esta manera, distinguiendo entre niveles generales y particulares, pueden esclarecerse algunos de los problemas que han dificultado la comprensión del fenómeno. Centraremos el análisis en un aspecto específico: el de las políticas públicas.

A través del artículo realizaremos dicho ejercicio para un caso concreto. Sostendremos que el concepto de movimientos nacional-populares puede utilizarse como una categoría de análisis que permite comprender a un tipo específico de populismo, un conjunto de movimientos políticos surgidos en América Latina, aproximadamente desde la tercera década del siglo $\mathrm{XX}$, y que vivieron su período de auge a mediados del siglo $\mathrm{XX}$, caracterizándose por combinar el reformismo social antioligárquico con el nacionalismo, a la vez que evidenciando características democráticas a la vez que antiliberales. Teniendo en cuenta dichos planteamientos, reflexionaremos sobre las posibilidades de asociar al populismo, en general, y a los movimientos nacional-populares, en específico, a un determinado tipo de políticas públicas.

Siguiendo la definición de Raul Velasquez Gavilanes, consideraremos como política pública al:

Proceso integrador de decisiones, acciones, inacciones, acuerdos e instrumentos, adelantado por autoridades públicas con la participación eventual de los particulares, y encaminado a solucionar o prevenir una situación definida como problemática. La política pública hace parte de un ambiente determinado del cual se nutre y al cual pretende modificar o mantener (Velásquez Gavilanes 2010: 167).

Con dicho fin estructuraremos el texto en tres secciones. En primer lugar, se situará el planteamiento en el marco de los debates recientes sobre el populismo. Siguiendo a autores como Cristobal Rovira y Cas Mudde 
(Mudde y Rovira 2012 2013), y adhiriendo a una definición universalista minina y de carácter ideacional, se considerará al populismo como una ideología maniquea que plantea una defensa radical del "pueblo" -en el cual radicaría la virtud- y de la soberanía popular, contra las élites consideradas como corruptas. En este sentido los movimientos nacionalpopulares serían una forma histórica, específica y concreta de populismo, que tendría su expresión en movimientos políticos, los que en algunos casos llegaron al poder y devinieron en regímenes.

Planteamos que, dada la amplitud de los tipos de fenómenos y orientaciones ideológicas de carácter populista, se vuelve imposible asociar un tipo de política pública específica al populismo. En este sentido, debatimos con las tesis monetaristas que, en el ámbito académico. han tendido a asociar al populismo a un determinado tipo de política pública, que a través de una política fiscal expansiva y desatendiendo los riesgos vinculados a las variables monetarias, apuntaría a la satisfacción inmediata de demandas sociales con fines electoralistas. Al respecto, sostendremos que dichas tesis corren el riesgo de estar cargadas de un fuerte sesgo normativo, desconociendo la variedad de políticas públicas implementadas y promovidas por corrientes populistas. Al mismo tiempo que corren el riesgo de confundir aspectos generales de las políticas económicas de determinados períodos históricos, especialmente entre las décadas de 1930 y 1970, con orientaciones de corrientes o lideres específicos (Sachs 1989, Edwards y Dornbush 1991).

En segundo lugar, serán analizadas algunas de las características centrales de los movimientos nacional populares y su ideología nacionalista antioligárquica, profundizando en los contenidos y formas particulares de aquel caso específico de populismo. Se sostendrá que los movimientos nacional populares se caracterizaron por defender ideas de nación antipluralistas; por rescatar elementos culturales atribuidos a grupos subalternos masivos como elemento central de la nacionalidad; por defender el principio de soberanía nacional como valor fundamental, llevándolo a diversos ámbitos de la política; y por su evidente tendencia al eclecticismo ideológico-intelectual.

En tercer lugar, se analizará la relación entre los movimientos nacionalpopulares y la democracia. Se sostendrá que los movimientos nacional populares tuvieron características democráticas y promovieron la integración política de sectores sociales subalternos excluidos en distintos grados. A la vez, manifestaron características antiliberales, manteniendo una relación conflictuada y tensa, aunque no de completa anulación, con el pluralismo político, relegándolo a un rol secundario. También se discutirá 
con los planteamientos que muestran a dicho tipo de movimientos como caudillistas y antiinstitucionalistas. $\mathrm{Al}$ respecto se seńalará la importancia que dieron a los procesos de institucionalización de sus movimientos y su labor de construcción institucional cuando llegaron al poder. Finalmente se señalará que, si bien algunos movimientos nacional populares mostraron evidentes tendencias caudillistas, este rasgo no fue compartido por todos $y$, por ende, no puede ser considerado como definitorio.

Sostenemos que dadas las características específicas de los movimientos nacional-populares -acotadas temporal y espacialmente- $y$ al hecho de que estos compartirían ciertas orientaciones ideológicas comunes, de carácter nacionalista-antioligárquico, si es posible vincularlos a determinadas orientaciones de política pública. Por lo demás, la promoción y aplicación de determinados tipos de políticas públicas fue fundamental, especialmente en su labor de incorporación de sectores excluidos.

Para concluir, en las reflexiones finales profundizaremos en las dificultades para asociar al populismo a un determinado tipo de políticas públicas. A la vez, sostendremos que, si bien dicho ejercicio puede realizarse con los movimientos nacional-populares, debe hacerse teniendo en ciertas prevenciones, como el evitar las tendencias a la generalización excesiva y a la confusión de las características de nuestro objeto de estudio con tendencias epocales más amplias.

\section{ENFOQUES IDEACIONALES Y DEFINICIONES MÍNIMAS EN EL MARCO DEL ESTUDIO DEL POPULISMO}

La profusión de estudios referidos al populismo ha convertido a dicho término en un concepto polisémico, sobre el cual existen las más diversas interpretaciones en los ámbitos de la politología y las ciencias sociales (Cortés y Pelfini 2017). El concepto ha sido utilizado para definir fenómenos de distinta naturaleza, tales como tipos de movimientos y regímenes, estilos de movilización social o de liderazgo y orientaciones de política económica (Mackinnon y Petrone 1999). A esto se debe añadir que existen interpretaciones divergentes en el modo de abordar estos fenómenos, las que se han visto marcadas por diferentes paradigmas ideológicos e intelectuales. A las disputas estrictamente académicas, cabe añadir el modo en que el término ha sido vulgarizado, esto pues en los debates políticos contingentes y en los medios de comunicación ha tendido a ser identificado de manera automática con características negativas (Kaiser y Álvarez 2016). En el ámbito latinoamericano se ha asociado a gobiernos que pretenderían satisfacer demandas sociales cortoplacistas, sin pensar en la estabilidad económica ni institucional a mediano plazo. Así, la irresponsabilidad fiscal 
y las políticas públicas orientadas a la generación de redes de clientelismo o, incluso, que implicaran un alto gasto fiscal han sido tildadas de esa manera. En Europa, por su parte, se ha asociado de manera creciente a partidos de derecha nacionalista y xenófoba, aunque recientemente también ha sido reivindicado por intelectuales pertenecientes a organizaciones emergentes de la izquierda que cuestionan el establishment monetarista imperante a través de la articulación de diversas demandas sociales particulares (Laclau y Mouffe 1987, Iglesias 2016). Así, en su uso corriente, el término ha llegado a ser confundido con el de demagogia. Es por estos motivos, que algunos autores han planteado la necesidad de abandonar su uso, por cuanto su ubicuidad y polisemia lo volverían inespecífico y por ende inútil para aprehender y categorizar casos específicos en una realidad diversa (Roxborough 1984: 14, Adamovsky 2015: 7).

En el ámbito latinoamericano, las transformaciones políticas que han tenido lugar desde la década de 1980, especialmente en elámbito de la política económica, han ejercido una importante influencia en el modo en que se ha categorizado al fenómeno. En este sentido, seguimos los planteamientos de Kurt Weyland (2001), quien ha sostenido que los estudios clásicos sobre el populismo latinoamericano, que emergieron principalmente desde la década de 1960, nacieron de la observación empírica de un tipo de realidad en un contexto específico: el de las sociedades latinoamericanas en el segundo tercio del siglo XX, aproximadamente. Aquellos estudios habrían apuntado a analizar movimientos y regímenes "multiclasistas", que generalmente tenían su núcleo fundamental en el movimiento obrero; que implementaban "políticas económicas desarrollistas", a la vez que "expandían los programas sociales" y que se asociaban a la "industrialización acelerada en sus fases tempranas y/o a la movilización social” (Weyland 2001: 6). También cabe mencionar que un punto fundamental que estuvo presente en gran parte de estas conceptualizaciones originales del populismo, tendía a resaltar la centralidad de la presencia de líderes carismáticos como un elemento definitorio del fenómeno (Conniff 1993: 32).

Sin embargo, dichas visiones se habrían visto tensionadas desde las décadas de 1980 y 1990, con la reemergencia de antiguos líderes considerados populistas y la aparición de nuevos dirigentes que utilizaban "estrategias políticas remanentes del populismo clásico para alcanzar y mantener el poder, a la vez que implementaban políticas neoliberales y buscaban eliminar los legados socioeconómicos del populismo clásico" (Weyland 2001: 7, Roberts 1995). Estas transformaciones permitieron la emergencia del concepto de neopopulismo y llevaron a que en las ciencias sociales surgieran periodizaciones, que expandían a la vez que seccionaban en el tiempo las transformaciones del populismo, y con ellas, hasta cierto, 
punto la historia política del siglo XX latinoamericano. En una síntesis de estas visiones, Michael Conniff (2003: 32) llegó a sostener que la historia del populismo latinoamericano podría ser dividida en tres períodos, estos serían, en primer lugar, el "populismo temprano, o quizás protopopulismo, en las primeras décadas del siglo 20 (1900 a 1920), especialmente en el cono sur". En segundo lugar, "el populismo clásico, de los años 40, 50 y 60, seguido por su aparente extinción a raíz de los regímenes militares de los 70 y 80 ". Finalmente, en tercer lugar, "el resurgimiento del populismo en los 80 y la aparición del neopopulismo en los 90".

Los cambios en la realidad histórica que servía de base empírica para la reflexión sobre el populismo, y los nuevos usos ampliados que comenzó a darse al concepto, generaron importantes debates al interior de las ciencias sociales y, en especial, de la politología (Reveco 1992). Esto pues no solamente aumentó la diversidad de interpretaciones referidas al fenómeno de estudio, sino porque también crecieron los cuestionamientos a la pertinencia del concepto (Knight 1998: 223-224). Con todo, el concepto ha logrado permanecer en uso en las ciencias sociales, a la vez que han surgido nuevas obras que han tematizado de manera más explícita el modo en que este ha sido construido. Al respecto es interesante volver sobre el análisis de Kurt Weyland (2001: 5). El autor sostiene que las definiciones tradicionales sobre el populismo, fundamentalmente las nacidas antes de las reformas neoliberales de las décadas de 1980-1990, tendieron a tener un carácter "acumulativo", "abarcando diferentes atributos prevenientes de distintos dominios" y dando una especial relevancia a la relación entre las "políticas populistas y sus raíces sociales", enfatizando en las condiciones estructurales que le dieron origen.

Sin embargo, la emergencia de fenómenos considerados como "neopopulistas", que poseían solo algunas de las características atribuidas en las definiciones clásicas, y la crisis de los paradigmas sociológicos en que se fundamentaban sus enfoques, principalmente las teorías de la modernización y de la dependencia, permitieron la emergencia de definiciones de carácter "radial", o incluso de intentos de redefinir el concepto de manera radical (Weyland 2001: 10). Esta idea, fue desarrollada con mayor profundidad por Kenneth M. Roberts (1995), quien a su vez utilizó una matriz conceptual basada en los trabajos de David Collier y James E. Mahon, Jr. (1993). Para Roberts, (1995: 88), las categorías radiales, estarían vinculadas a un "caso prototípico" el que "aportaría un conjunto de elementos o propiedades centrales". Al mismo tiempo, las "categorías secundarias (o subtipos)", serían "variantes del caso prototípico" y "compartirían con el algunos (pero no todos) sus atributos definitorios". 
El escenario generado por las transformaciones del concepto de populismo, sumado a la creciente importancia que han adquirido en el debate las definiciones de carácter radial, han llevado a que, desde la década de 1990, se produzca un aumento del número de interpretaciones del fenómeno y, lo que es aún más importante, de las definiciones sobre la naturaleza del mismo ${ }^{1}$. Las visiones clásicas, emergidas en las décadas de 1960 y 1970, vinculadas a la teoría de la modernización y a los enfoques estructural-funcionalistas, analizaron al populismo como un tipo específico de movimiento político, relacionándolo directamente a los procesos de modernización en sociedades consideradas como "atrasadas". Fue el caso de las interpretaciones de Gino Germani y Torcuato di Tella. También en esos ańos, otro grupo de autores, la mayoría de ellos, aunque no todos, influidos por la teoría de la dependencia, analizó al populismo como un arreglo entre diversos actores sociales, constituyendo un modelo de relaciones sociales que actuaría como el correlato de modelos económicos específicos. Ambos enfoques, calificados por Claudio Riveros (2018: 64) como "sociológico-históricos" tendían a construir conceptualizaciones acumulativas y se encontraban directamente vinculados al estudio de la realidad latinoamericana del segundo tercio del siglo XX.

Sin embargo, desde la década de 1990 en adelante, han surgido nuevos enfoques, caracterizados por su afán de construir categorías de tipo radial y por los intentos de redefinir el concepto. Los distintos enfoques utilizan el término populismo para definir fenómenos que, en muchos casos, son de naturaleza diferente. De este modo, algunos autores han utilizado el concepto para definir un tipo de "estilo político", siguiendo un enfoque "relacional”; una "estrategia de poder", según un enfoque institucionalista”; un "tipo de política económica", en un enfoque que hemos denominado como "monetarista ortodoxo"; un tipo de "ideología" según el enfoque "ideacional" o una "lógica discursiva", según un enfoque "políticodiscursivo" (Riveros 2018: 64). Existe también un "enfoque sociocultural”, que se centra en los elementos "performativos" y de carácter "afectivo" movilizados por el populismo (Ostiguy 2017). Dicha orientación puede incluirse como parte de los enfoques relacionales, en cuanto los "estilos" políticos son un elemento central en su interpretación.

Dada la amplitud de la bibliografía y la extensión de este trabajo, resulta imposible detenerse en un análisis profundo de cada una de las corrientes recién nombradas. Por este motivo, nos abocaremos a justificar

1 Para realizar esta síntesis de los principales enfoques de estudio sobre la naturaleza del fenómeno populista, nos hemos basado principalmente en el texto de Claudio Riveros, de quien hemos tomado su orden y categorización (2018: 64-85). 
nuestra elección de perspectiva teórica, mencionando brevemente, los planteamientos de los enfoques relacional, institucionalista y monetarista ortodoxo, a través de algunos de sus exponentes representativos y enunciando los reparos que planteamos a dichas interpretaciones. Con posterioridad describiremos el "enfoque ideacional", explicando el por qué lo consideramos como el más acertado para analizar al populismo².

En el caso del enfoque "relacional", que analiza al populismo como un "estilo político", cabe mencionar la definición de uno de sus principales exponentes Michael Conniff(1999:4), quien ha sostenido que el populismo sería "un estilo expansivo de campaña electoral desarrollado por políticos coloridos y atrayentes". Este "podría atraer nuevas masas de votantes a sus movimientos y mantener su lealtad de manera indefinida, a veces incluso después de sus muertes". Por su parte, el enfoque "institucionalista" ha tendido a privilegiar el estudio del populismo como una "estrategia política. Como ha sostenido Kurt Weyland, uno de sus principales exponentes, en el marco de una entrevista realizada por Jenny Ponton Cevallos (2016: 164), dicha estrategia se basaría en "un liderazgo personalista muy fuerte". Esto pues "se trata de un líder que llega al poder y se mantiene ahí con base en vínculos no organizados con una masa heterogénea de seguidores". Para Weyland, "los elementos típicos del populismo son el liderazgo personalista y la falta de institucionalización del vínculo con los votantes". Esta situación, haría que el populismo tuviese "una base bastante fluida, no muy sólida, en términos de sustentación" (Weyland en entrevista de Ponton Cevallos 2016: 164). Según Weyland (2001: 12), dicho enfoque "precisaría las visiones centradas en el estilo político", en cuanto consideraría a los líderes que "que sustentan su poderío en un cierto tipo de capacidad de poder, y no solo en aquellos que ocasionalmente utilizan aquella capacidad".

Podemos hacer importantes cuestionamientos, tanto a los enfoques relacionales como a los institucionalistas. ¿Hasta qué punto la utilización de liderazgos carismáticos, que apelan a sus atributos personales y a la "cercanía" con el electorado, no son elementos propios de la política de masas moderna surgida al alero del sufragio universal? ¿No corre el riesgo de convertir al análisis de la presencia del populismo en una medición de efectividad de objetivos propios de la mayor parte de las candidaturas en una democracia competitiva? En un sentido similar, en el caso del enfoque institucionalista, cabe señalar que la falta de institucionalización

2 Más adelante, en el texto y en las notas al pie, señalaremos como el enfoque "político-discursivo" puede ser complementario con el ideacional. Si bien el término "ideacional” constituye un neologismo, consideramos que es la traducción más exacta del término original en inglés: ideational. 
en el vínculo con los votantes, es un tópico que ha tendido a ser matizado por estudios, usualmente politológicos o sociológicos, todos ellos con un fuerte énfasis histórico, que se han centrado en el análisis en las bases de apoyo de los líderes considerados como populistas. Por lo demás, dicha visión no da cuenta de la efectiva capacidad de negociación y organización que efectivamente han demostrado los seguidores de estos movimientos ${ }^{3}$. Hasta cierto punto, dichas visiones dan continuidad a los planteamientos realizados por algunos estudios clásicos del populismo como el de Germani (1965), quien consideraba a los seguidores de los movimientos populistas como "masas disponibles", sin atender a su racionalidad ni su agencia. Dichas visiones hacen eco de una tendencia que ha sido denominada por Ernesto Laclau (2007) como "denigración de las masas", que hundiría sus raíces en la psicología de masas de inicio del siglo XX y sus visiones temerosas de la masificación de la política ${ }^{4}$.

En el caso del enfoque "monetarista ortodoxo", este ha enfatizado en que los rasgos distintivos del populismo radicarían en las políticas fiscales expansivas, con una evidente predisposición a la satisfacción de demandas sociales por sobre el control de las variables monetarias. Así, Rudiger Dornbusch y Sebastián Edwards (1989: 1) han señalado que entienden por “"populismo", un enfoque de la economía que enfatiza la "redistribución del crecimiento y los ingresos y desensibiliza los riesgos de la inflación y la financiación del déficit, las limitaciones externas y la reacción de los agentes económicos a políticas agresivas no de mercado". El problema de dicho enfoque, es que abunda en prescripciones de análisis normativo, generando un adjetivo denostativo antes que una categoría con valor analítico. Esto pues elabora un concepto extremadamente amplio, en el cual cabrían gobiernos disimiles que tenían en común regirse por las condiciones y las ideas económicas, principalmente keynesianas, que fueron hegemónicas con posterioridad a la crisis de 1929 y hasta, aproximadamente, la década de 1970 (Edwards y Dornbush 1991). De la misma manera, como se ha evidenciado en el período posterior a 1990, políticas monetaristas y

3 Al respecto, es relevante señalar el aporte que han realizado los estudios de la experiencia peronista en Argentina. Varios de ellos, rompiendo con la tónica imperante en las ciencias sociales desde la década de 1960, han enfatizado en los importantes grados de organización, institucionalización y adhesión a tradiciones políticas que ya poseían las bases que constituyeron el peronismo antes de organizarse. Al respecto, véase Juan Carlos Torre (2012), quien aborda las relaciones entre el sindicalismo y el peronismo, y Moira Mackinnon (2002), quien trata los orígenes del Partido Peronista.

4 Para una visión en el largo tiempo de la relación entre intelectuales y masas, véase Carey (1992). 
promercado se han podido ver asociadas a gobiernos y movimientos que han evidenciado las características centrales del populismo. Un caso importante desde fines del siglo XX ha sido el de la Liga del Norte en Italia. En su reivindicación de los valores de la Italia del norte ha combinado sus invectivas antieurpeistas y su discurso antiinmigratorio con la defensa de políticas promercado y opuestas al Estado de bienestar (Diani 1996).

Es en este sentido que optamos por un enfoque "ideacional", y una definición mínima para abordar el concepto de populismo. Como ha sostenido Cas Mudde (2017) el "enfoque ideacional" considera al populismo como una "ideología". Al momento de realizar la definición, Mudde se basa en la definición de ideología de Diane Sansbury, quien sostiene que esta sería un "cuerpo de ideas normativas y sobre la naturaleza del hombre y la sociedad, así como sobre la organización y los propósitos de la sociedad". Se trata de una definición amplia y mínima, que da cabida a diversos tipos de ideología, además de estar, en términos relativos, más libre de implicancias normativas. Estas prevenciones son importantes pues, como sostiene Mudde, el populismo sería una ideología "escueta", sin el mismo nivel de "refinamiento intelectual" que ideologías más "complejas" "como el socialismo o el liberalismo" (Mudde 2017)5 . El enfoque ideacional presentaría importantes ventajas, en cuanto genera las condiciones apropiadas para construir definiciones mínimas, debido a que considera un elemento común y no exclusivo a las diversas experiencias políticas. Por lo demás, esta orientación permite sintetizar los aportes de la mayor parte de los otros enfoques. Esto pues, como han señalado Rovira Kaltwasser y Hawkins (2017: 515), casi todas las interpretaciones sobre el populismo "incorporan [al tratarlo] la noción de un conjunto subyacente de ideas".

Además de tributar al enfoque ideacional, recurriremos a una definición mínima de populismo. Esta nos permitirá reconocer la capacidad que dicho fenómeno presentó para emerger en diversos tiempos y circunstancias, a la vez que distinguir las formas específicas que este tuvo en el marco de los fenómenos y lugares estudiados. En este aspecto, coincidimos con la crítica planteada por Christa Deiwks a los intentos de generar definiciones de populismo con una amplia cantidad de elementos, en cuanto limitarían la aplicabilidad del término a número muy reducido de casos contingentes, disminuyendo su utilidad analítica (Deiwiks 2009: 2). Por este motivo,

5 En sus textos Mudde y Rovira Kaltwasser urilizan en el término thin o thin-centred ideology. Por nuestra parte, consideramos al término "escueto" como la traducción más apropiada, pues reflejaría mejor el sentido que los autores buscarían darle al término, refiriéndose a su exigua elaboración y escasez de contenidos. 
nos basaremos en las conceptualizaciones de carácter mínimo sobre el populismo, realizadas por Margaret Canovan, en menor medida por Donald MacRae, y, especialmente, por Cass Mudde y Cristobal Rovira Kaltwasser. Cabe aclarar que utilizaremos el término populismo en cuanto categoría de análisis. Esto pues la mayor parte de los actores que los estudiosos del populismo han considerado en sus trabajos, no utilizaron dicho concepto como marcador de identidad ni de autoadscripción. Por el contrario, en este contexto, su uso corresponde al de una categoría generada desde los ámbitos de la teoría política y las ciencias sociales, destinada a identificar determinados tipos de fenómenos políticos.

Buscando una definición mínima, que permita englobar a las diversas experiencias históricas que han sido caracterizadas como populistas, Canovan (1993: 3) sostuvo que el populismo implicaría algún tipo de "revuelta, en nombre del pueblo, contra las estructuras de poder establecidas" y, específicamente, un "desafío a los valores de la élite”. Según la autora "toda forma de populismo, sin excepción, implica algún tipo de apelación 'al pueblo', y en algún sentido u otro, todas son antielitistas" (Canovan 1981: 294).

Apoyándose, en parte, en la conceptualización de Canovan, y poniéndola en relación con otros fenómenos políticos, Mudde y Rovira Kaltwasser, han sostenido que el populismo es una "ideología escueta, la que no solamente se basa en una distinción maniquea entre "el pueblo puro" y la "élite corrupta", sino que también en la defensa de la soberanía popular a toda costa" (Mudde y Rovira Kaltwasser 2013). Así como los conceptos de "pueblo", "élite" y "voluntad general" constituirían el núcleo central de la ideología populista, esta tendría dos conceptos antitéticos: el elitismo y el pluralismo (Mudde y Rovira Kaltwasser 2012: 9). Desarrollando aquella definición, los autores plantean que el populismo sería fundamentalmente un modo moralista de entender la política. Esto debido a que "la distinción entre 'la élite' y 'el pueblo', tendría antes que nada un carácter moral" (Mudde y Rovira Kaltwasser 2012: 8).

Consideramos que esta dimensión moral de la política populista tiene consecuencias en el modo en que valora y se relaciona con las temporalidades políticas. Esto pues implica una aceptación y exaltación del "pueblo", y las características que se le atribuyen en un momento específico, que puede encontrarse en el presente o en un pasado idealizado, diferenciándose de las ideologías que promueven políticas de regeneración y transformación de "lo popular" en el tiempo. En contraposición, el populismo enfatiza de manera presentista en las características supuestamente positivas del "pueblo", o pretende, de manera proyectual, recuperar las virtudes de este 
que habrían sido negadas por "la élite" (MacRae 1969: 160).

Con respecto a las características que se les atribuyen a los campos antagónicos a través de los cuales el populismo representa a la sociedad, creemos que estos son contingentes y pueden variar en distintos tiempos y lugares. En este punto, coincidimos con Rovira Kaltwasser y Mudde, cuando plantean que las categorías fundamentales para el populismo pueblo y élite - podrían asimilarse a los "significantes vacíos" desarrollados en su obra por Ernesto Laclau (Montero 2012: 5, Laclau 2007: 114, Laclau 2006). Esto en cuanto serían los populistas quienes construirían los significados específicos de dichos términos. Esta situación volvería al populismo "lo suficientemente maleable para adoptar distintas formas en tiempos y lugares diferentes, permitiendo que se pueda vincular a ideologías de diverso signo" (Mudde y Rovira Kaltwasser 2012: 9). Es en este sentido que el mensaje antielitista del populismo podría desarrollarse en el marco de diversos tipos de ideología de acogida (Mudde y Rovira Kaltwasser 2012: 2).

En este sentido, movimientos y gobiernos de carácter populista no pueden asociarse necesariamente políticas públicas determinadas con contenidos específicos. Al tratarse de una ideología "escueta", el populismo puede vincularse a sectores políticos de diverso signo ideológico, con una amplia variedad de orientaciones programáticas, lo que puede influir en orientaciones de política pública distintas.

En la actualidad, gobiernos en Europa que evidencian características definitorias del populismo, como la defensa del "el pueblo puro", contra las "élites corruptas" y su cosmopolitismo implementan políticas públicas que promueven la segregación y diferenciación de la población. Es el caso de Hungría actual en relación a los migrantes y minorías étnicas, donde las políticas públicas han tendido a quitar beneficios afectando sus condiciones de vida (Fekete 2016). Sin embargo, como veremos más adelante, en otros contextos, como el latinoamericano de mediados del siglo XX, las políticas públicas de gobernantes populistas tendieron a promover la incorporación de sectores excluidos.

Cabe señalar que también, discrepamos de las corrientes que, al momento de analizar la actuación de gobiernos que pueden calificarse como "populistas", tienden a considerar a sus políticas públicas como herramientas destinadas a "ayudar a políticos a manipular a las masas", según ha planteado Nagin Bavili (2017: 432) en su estudio sobre el policy making en contextos populistas, para el caso iraní. Esta visión, que ha analizado las políticas de bienestar atribuidas a gobernantes populistas 
como "medios para atraer votantes en con el fin de alcanzar ciertas metas", se centra exclusivamente en problema vinculados al estilo político y confunde populismo con clientelismo. Por lo demás no tiene en cuenta la agencia y capacidad negociadora ni las complejidades de la racionalidad política de los sectores beneficiarios de políticas sociales.

\section{LOS MOVIMIENTOS NACIONAL-POPULARES Y EL NACIONALISMO ANTIOLIGÁRQUICO}

Una vez que hemos aclarado y situado en los debates académicos la noción de populismo que utilizaremos, realizaremos una caracterización de los movimientos nacional-populares para reflexionar sobre sus políticas públicas. A diferencia de la definición ideacional y de carácter mínimo a la que acudimos para abordar el populismo, en el caso del concepto movimientos nacional-populares, identificaremos un número mayor de características particulares. Construiremos una categoría de carácter acumulativo, dado que definirá un fenómeno más específico, que tuvo lugar en un período y una región acotadas y que, por ende, posee aspiraciones de generalización de alcance medio (Merton 1968) y no de carácter universalista.

Así, utilizaremos el término movimientos nacional-populares para designar a los movimientos políticos surgidos en América Latina desde la tercera década del siglo XX, y que vivieron su apogeo entre las décadas de 1940 y 1950, los que combinaron el reformismo social antioligárquico con el nacionalismo y que evidenciaron características a la vez nacionalistas y antiliberales.

El término nacional-popular no es nuevo en la literatura de la politología y las ciencias sociales latinoamericanas. En diversas conceptualizaciones clásicas este ya había sido utilizado indistintamente como sinónimo de populismo. La tendencia al uso de dicha categoría fue notoria especialmente entre las décadas de 1960 y 1980, en un contexto intelectual en el cual las definiciones de carácter acumulativo eran hegemónicas. Como ha sostenido Claudio Riveros (2018: 47), Gino Germani ya había utilizado el término, valiéndose de este para aludir a "los movimientos movilizadores y fundacionales que se generaron en América Latina, en el marco de un proceso de ruptura con el Estado Oligárquico”. En todo caso, el término precede a Germani, estando presente en la tradición gramsciana, y si bien no existen indicios de una filiación intelectual directa entre Germani y Gramsci, si pueden evidenciarse algunas similitudes en el modo en que han abordado el problema (Varela Petito 2008: 242, Portantiero 1991: 153-154, Portantiero y De Ipola 1981: 52). En la actualidad, existen autores, como Hugo Cancino (2012) y Claudio Riveros (2018), quienes 
han revalorizado su uso. En nuestra opinión, la puesta en valor de dicha conceptualización puede asociarse a elementos contextuales contingentes desde la década del 2000, como la emergencia de movimientos políticos que poseen rasgos similares a los del populismo clásico y que adquirieron una actitud contestaría hacia la hegemonía monetarista imperante, como fue el caso de Venezuela, Ecuador, Bolivia y Nicaragua.

Como el concepto de movimientos nacional-populares al que recurriremos se asimila en varias de sus características a las de los denominados populismos clásicos latinoamericanos, se vuelve necesario realizar algunas precisiones al respecto, especialmente en referencia a la naturaleza del fenómeno que vamos a estudiar. Consideramos necesario plantear que nuestra conceptualización se aparta de las definiciones que tienden a analizar al populismo como un arreglo o compromiso de poder entre fuerzas sociales, llegando a constituir una fase histórica. Entre dichas definiciones se encuentran las realizadas por Francisco Weffort (1967) y por Faletto y Cardoso (1969). Con diferencias, ambos trabajos vieron en el populismo la expresión política de los acuerdos entre fuerzas sociales discordantes, incapaces de lograr hegemonía en el marco de procesos de incorporación popular e industrialización.

Weffort (1967) asoció su noción de populismo a la de Estado de Compromiso. Así, al analizar la política brasileña sostuvo que el "equilibrio inestable entre los grupos dominantes y esencialmente, la incapacidad de cualquiera de ellos de asumir, como la expresión del conjunto de la clase dominante del control de las funciones políticas", constituirían las "condiciones" de "los rasgos relevantes de la política brasileña en ese momento" y "componentes de lo que se convertirá esencial en el populismo". Por su parte, poniendo énfasis en los procesos de industrialización sustitutiva, para Faletto y Cardoso (1969), el "populismo desarrollista" sería la expresión de "intereses contradictorios: consumo ampliado-inversiones aceleradas, participación estatal en el desarrollofortalecimiento del sector urbano-industrial privado" entendiéndolo como un "acuerdo" de "fuerzas sociales. Quizás, quien expresó dicha visión con mayor claridad fue Octavio Ianni (1973), quien sostuvo que:

Así, en varios aspectos, el populismo latinoamericano se corresponde a una etapa determinada de la evolución de las contradicciones entre la sociedad nacional y la economía dependiente. La naturaleza del gobierno populista (que es en donde se expresa más abiertamente el carácter del populismo) se localiza en la búsqueda de una nueva combinación entre las tendencias del sistema social y las imposiciones de la dependencia económica (Ianni 1973: 85-86). 
Nuestra conceptualización también discrepa de otras interpretaciones, como la realizada por Alain Touraine a fines de la década de 1980, para quien lo nacional-popular sería un tipo de "política" y un modo de intervención del Estado. Para Touraine, la emergencia de lo "nacionalpopular" se vincularía a la incapacidad de los actores sociales de distinguir sus intereses e identidad de manera autónoma, en el marco de una estructura de clases escasamente definida. De este modo sería una suerte de "reacción" de carácter "nacional" contra las "modernizaciones dirigidas desde el exterior". Así, en América Latina, hasta la década de 1980, lo nacional-popular sería un tipo de política (una "política nacional-popular" en palabras de Touraine (1989). Así, para el autor, la forma de intervención social del estado más característica del modelo latinoamericano es la política nacional popular. Esta combinaría "tres temas: independencia nacional, modernización política e iniciativa popular. El populismo es la identificación del movimiento con el estado y por eso se define mejor como una política" (Touraine 1999).

Consideramos que los tipos de conceptualizaciones recién mostrados promueven una tendencia a la indeterminación al utilizar el término, transformando a este en una suerte de "signo de los tiempos" epocal, que terminaría incluyendo a fenómenos de la naturaleza más diversa. En este punto coincidimos con Roxborough (1984), en cuanto dicha situación le resta valor analítico.

Es necesario aclarar que, al referirnos a lo nacional-popular estamos haciendo alusión a un tipo de movimiento político, englobando bajo este término tanto a la organización como a los apoyos que es capaz de movilizar, el que eventual, aunque no necesariamente, puede acceder al gobierno y devenir en un "régimen", llegando a caracterizar "fases estatales" (Portantiero y De Ipola 1981: 54). Hacemos esta prevención, en cuanto consideramos necesario realizar un análisis histórico de estos movimientos tanto en los momentos en que se encuentran fuera de los gobiernos, como cuando participan en estos y cuando logran orientarlos y constituir "regímenes" (Riveros 2018). De esta manera, definimos al fenómeno por sus características y no por una medición de su efectividad realizada ex post facto. Esto permite que al momento de realizar el análisis podamos tener en cuenta las alternativas que debieron enfrentar los actores en su circunstancia histórica.

Sostenemos que los movimientos nacional-populares tienen características populistas, en cuanto evidenciaron una pronunciada disposición antielitista. Esta adquirió centralidad en su discurso, planteando una distinción de carácter moral entre el pueblo y las élites. Sin 
embargo, consideramos que dicho atributo no basta para definirlos, pues también puede ser compartido por otros tipos de corrientes y movimientos políticos de carácter populista. Por este motivo, consideramos relevante indagar en los contenidos y las formas ideológicas específicas que adquirió el populismo en aquellos movimientos, lo que nos permitirá comprender el modo en que definió sus nociones de élite y pueblo.

Sobre este último aspecto, es necesario señalar que las formas ideológicas que adquirieron los movimientos nacional-populares fueron nacionalistasantioligárquicas: críticas a las oligarquías y su concentración del poder político y económico, a su cosmopolitismo y, con distintas intensidades, a sus mecanismos de distinción social. En contraposición, desarrollaron tendencias democratizantes, apelando a la participación e integración de actores sociales excluidos de carácter masivo y reivindicado, en grados diferentes, sus valores y expresiones culturales, a las que identificó como las propias de la nación. Sin embargo, en su reivindicación de la soberanía popular como valor supremo, y en su afán de identificar a la "nación" con un sector de esta, evidenciaron un carácter antiliberal, que se reflejaba en una relación conflictuada con el pluralismo político y con las garantías individuales, que eventualmente representasen un freno a la voluntad mayoritaria.

Con todo, antes de señalar las características específicas de la ideología nacionalista-antioligárquica de los movimientos nacional-populares, debemos aclarar que utilizamos el concepto de nacionalismo en cuanto ideología. Al mismo tiempo, consideramos necesario señalar que, en el caso que estudiamos, esta ideología nacionalista estaría asociada, en distintos grados, al rescate de elementos culturales particularistas, y no sería exclusivamente política. (Breully 1982: 11, Hutchinson 1987: 122123, Hobsbawm 1983: 6).

Debemos aclarar que no pretendemos hacer un ejercicio genealógico, centrado en la búsqueda de las fuentes y la descripción de los procesos de circulación de las ideas nacionalistas-antioligárquicas. Por el contrario, aspiramos a realizar un ejercicio de tipologización, en el que tendemos en cuenta elementos comunes entre sí de las principales ideas de los movimientos nacional-populares, a la vez que distintivos respecto a otras ideologías. En este mismo sentido, prestaremos atención tanto a ideas intelectualizadas de manera explícita, como a aquellas que puedan desprenderse de sus prácticas, discursos y políticas.

Teniendo en cuenta estas prevenciones, podemos pasar a enunciar las principales características de la ideología nacionalista-antioligárquica 
que distinguiría a los movimientos nacional populares. Estas serían, en primer lugar, la definición de una idea de nación esencialista, unívoca y antipluralista. En segundo lugar, el rescate y ensalzamiento de elementos culturales atribuidos a grupos subalternos masivos como elemento central de la nacionalidad. En tercer lugar, el reconocimiento del principio de soberanía nacional como valor fundamental y su capacidad de expandirlo a los más diversos ámbitos de la política. En cuarto lugar, una marcada tendencia al eclecticismo ideológico-intelectual.

Con respecto al primer punto, referido a cómo el nacionalismo antioligárquico define una idea de nación esencialista, unívoca y antipluralista, debemos señalar que esta se deriva de la naturaleza populista de la ideología de los movimientos nacional-populares. Como ha sostenido James D. Ingram (2017: 247), la apelación al "pueblo" siempre implica la reivindicación de un elemento de identidad particular". Por ende, "necesariamente debe referir a una identidad concreta" y "no puede ser universal o totalmente inclusiva". Es ente sentido, que los movimientos nacional-populares se caracterizan por su anticosmopolitismo. Así, su nacionalismo necesariamente apunta a la reivindicación de elementos culturales subjetivos, como los valores y hábitos de un sector de la población. Estos son asumidos como los propios de la "nación" entera, para ser contrapuestos a otros, propios de una "élite", la que pasaría a ser considerada extranjerizante (Bohoslavsky 2017).

En segundo lugar, reforzando y explicados los contenidos del punto anterior, el nacionalismo antioligárquico rescata y enarbola elementos culturales tradicionalmente atribuidos a grupos subalternos. En efecto, el nacionalismo antioligárquico puso en cuestión diversos supuestos culturales en torno a los cuales se llevaron adelante los procesos de construcción nacional decimonónicos, principalmente en lo referido a su carácter elitista y cosmopolita. Siguiendo nuevamente a Ernesto Bohoslavsky, podemos sostener que aquellos movimientos se caracterizarían por el "rescate de elementos identitarios nacionales que habían quedado en buena manera sumergidos o negados por las lecturas previas hegemónicas" (Bohoslavsky 2017). Sin embargo, a estas últimas contrapuso a estos un nuevo ideal nacional, que pretendía rescatar elementos de origen popular en cuanto elemento central de identidad. En este sentido, podemos considerar que el nacionalismo de dichos movimientos posee una naturaleza dual, que apela a la vez a la integración y la confrontación. Si bien dicha naturaleza no es completamente contradictoria, si puede generar tensiones en su interior. Esto pues apelan "el sentimiento de pertenencia nacional" el que cumpliría con "una función de integración muy importante, ya que asegura la cohesion entre grupos diversos" (Germani 1973: 33), a la vez 
que define como núcleo de dicha identidad a los atributos de sectores hasta el momento considerados como oprimidos o excluidos. Así, el fin último del conflicto socio-político pasa a ser la lucha contra determinados sectores en cuanto estos son considerados como los enemigos de la nación.

Teniendo en cuenta la naturaleza dual de esta ideología, cabe mencionar que sus contenidos específicos pueden variar en sus diversas expresiones concretas. En distintas experiencias nacional-populares pueden adquirir centralidad ciertos actores subalternos y otros pueden ver minimizada su importancia. A la vez, elementos culturales particulares, propios de actores determinados, pueden recibir una importancia especial. Así, algunas experiencias podrán dar más relevancia a la etnia y a la vez otros a la clase $\mathrm{u}$ a otras formas de identificación. El obrero, el campesino, el indígena, o incluso otras representaciones más generales del pobre urbano, tendrán distintos grados de relevancia en diferentes movimientos y momentos. Por lo demás, el modo en que rescata a dichos elementos específicos puede ir variando en el tiempo. Esta plasticidad que la ideología nacionalistaantioligárquica evidencia al momento de invocar elementos identitarios provenientes de distintos actores sociales se ve facilitada por la primacía que adquieren en su vocabulario conceptos de orden más bien general, como los de pueblo y nación, los que, en términos de Laclau, actuarían como significantes vacíos (Laclau 1996, Laclau 2007). Así, movimientos como el peronismo tendieron a dar centralidad al movimiento obrero, llegando incluso a catalizar la emergencia de una identidad clasista entre los obreros argentinos (James 2010), otros como la Acción Popular Revolucionaria Americanista (APRA), partido político indoamericanista fundado en Perú en 1924, reivindicaron al campesino en cuanto indígena (Kantor 1966), a la vez que, en Bolivia, el Movimiento Nacionalista Revolucionario (MNR) -partido reformista y nacionalista formado en Bolivia en 1942- desarrolló, desde la segunda mitad de la década de 1940, una fuerte ligazón con obreros y más tardes con campesinos, pero sin dar el mismo énfasis en su identidad indígena (Gotkowitz 2008).

Dicha situación nos lleva a tematizar un aspecto abordado por algunos autores, cual es el "componente socio-cultural" de carácter "afectivo" en los populismos y como este se expresa en el caso de los movimientos nacional-populares. En un enfoque que ha definido como "socio-cultural", Pierre Ostiguy $(2009,2017)$, sostiene que el populismo emergería como una reivindicación de los elementos culturales identitarios de los sectores "bajos", en cuanto un "otro impresentable", la que se contrapone a la "corrección política" y a los elementos de distinción social de la élite. Para Ostiguy, la oposición entre un pueblo "autentico" excluido y una élite "nefasta", es más exacta que la dicotomía entre un pueblo "puro" y 
"virtuoso" y una élite "corrupta", en cuanto en el populismo se exaltaría la dimensión impresentable de lo socialmente "bajo". Coincidimos con Ostiguy, en cuanto el cuestionamiento a las élites y de muchos de sus signos de distinción social, a la vez que el rescate de elementos culturales asociados a actores "populares" es un elemento presente en los movimientos nacionalpopulares. Sin embargo, el afán de ensalzar los elementos "impresentables" de determinados sectores populares está presente solamente en algunos movimientos nacional-populares, mientras otros efectivamente buscan reivindicar virtudes y pureza moral en ellos. Así, los diversos movimientos nacional populares mantuvieron una tónica antioligárquica. Si bien algunos de ellos, como el APRA, buscaron la pureza en la comunidad Indígena, y otros como el MNR, mantuvieron cierto tono heredado de las costumbres de las clases medias urbanas. También hubo movimientos como el peronismo que apelaron constantemente a los elementos más disruptores y chocantes atribuidos a la cultura popular.

En tercer lugar, sobre el modo en que la ideología nacionalistaantioligárquica reconoce el principio de soberanía nacional como valor fundamental, expandiéndolo a los más diversos ámbitos, cabe mencionar las reflexiones de Hugo Cancino, quien sostiene que el nacionalismo de los movimientos nacional populares se expresaría en la constante "reafirmación del principio de soberanía nacional" (Cancino 2012). Este no sería entendido de un modo exclusivamente político, sino también en los ámbitos de la economía y de la cultura. Se trata de un punto de importancia fundamental, en cuanto los movimientos nacional-populares pretendían hacer del particularismo nacional, en marco del concierto internacional, un elemento fundamental del proyecto político (Bohoslavsky 2017).

En este sentido, cabe destacar la fuerza que en sus discursos y programas adquirieron la política de nacionalización de recursos naturales o industrias estratégicas. Actos como la nacionalización de los ferrocarriles por parte del régimen peronista y la nacionalización de las minas de estaño, realizada por el MNR tras la Revolución Nacional, fueron convertidos en hitos simbólicos de sus regímenes (Dunkerley 1984).

Este punto también se evidencia en como el nacionalismo de los movimientos nacional-populares tendió a mostrarse "a la vez antimperialista y anticomunista" y "según los períodos, es uno u otro el que predomina, incluso en el curso de la historia de un mismo movimiento" (Löwy 1989: 7). No es de extrañar que, si bien dichos movimientos mantuvieron vínculos internacionales, no ingresaron formalmente a organizaciones políticas partidarias internacionales durante el período. Por lo demás, cuando intentaron generar vínculos, o establecer instancias de 
coordinación internacionales, lo hicieron enarbolando posturas terceristas y privilegiando el vínculo con actores latinoamericanos, tercermundistas, o que al menos tuviesen un grado de involucramiento menor con los grandes bloques internacionales, especialmente aquellos que vinculaban al imperialismo y al capitalismo liberal o al comunismo. Esto se nota en los intentos del APRA por convertirse en un partido continental, en los esfuerzos del peronismo por articular fueras políticas latinoamericanas defensoras de la "tercera posición" o en los vínculos del MNR con fuerzas políticas reformistas y socialistas no comunistas latinoamericas (Zanatta 2013, Dunkerley 1984, Bergel 2009).

En cuarto lugar, sobre su tendencia al eclecticismo ideológico-intelectual., consideramos pertinente rescatar una reflexión de Gino Germani, en cuanto algunas de las características principales de los movimientos nacional-populares::

Parecen ser el autoritarismo, el nacionalismo y alguna otra forma del socialismo, del colectivismo o del capitalismo de Estado: es decir, movimientos que, de diversas maneras, han combinado contenidos ideológicos opuestos. Autoritarismo de izquierdas, socialismo de derechas y un montón de fórmulas híbridas y hasta paradójicas, del punto de vista de la dicotomía (o continuidad) "derecha-izquierda". Son exactamente las fórmulas que, pese a su diversidad y contradicción en muchos sentidos, pueden ser apuntadas bajo la denominación común de movimientos nacional populares (Germani 1973: 29).

El grado de articulación intelectual y sofisticación ideológica varió entre los movimientos nacional-populares, pasando desde la escasa elaboración de algunas ideas-fuerza justicialistas del peronismo, hasta las refinadas y complejas tesis sobre el indoamericanismo de los apristas peruanos. Sin embargo, todos, en su afán reivindicar una política autocentrada, tendieron a evitar la adscripción a modelos ideológicos rígidos y desarrollaron corpus ideológicos que tomaban elementos de diversas proveniencias. Con todo, si bien variaron en intensidad tanto entre los distintos movimientos, como al interior de estos a lo largo del tiempo; existen ciertos elementos que estuvieron presentes en todos los movimientos nacional-populares. Estos son el nacionalismo, el reformismo antiolgárquico y el antiliberalismo.

\section{DEMOCRATIZACIÓN Y ANTILIBERALISMO}

Junto con su carácter nacionalista y antioligárquico, otro aspecto ideológico que distingue a los movimientos nacional-populares es su compleja relación con la democracia y el liberalismo. Sostenemos que los movimientos 
nacional-populares tienen un carácter democrático en cuanto recurrieron a mecanismos eleccionarios para legitimar su autoridad, enarbolaron un cuerpo de ideas y un discurso que ponía su acento en la voluntad popular y en las mayorías, e implementaron políticas que propendieron a la incorporación política y la ciudadanización de sectores subalternos de carácter masivo, tanto en el ámbito de los derechos civiles y políticos como de los derechos sociales.

Como mencionábamos recién, el proceso de ciudadanización excedió la esfera de los derechos políticos, incorporando el ámbito de los derechos sociales. En este sentido, las políticas públicas de los movimientos nacionalpopulares, una vez que llegaron al poder, apuntaron a la integración social y a la expansión de beneficios sociales.

En este aspecto, un caso interesante a analizar es el de las políticas de bienestar social implementadas en Argentina durante el primer peronismo. Si bien existe un debate importante entre los estudiosos de las policías sociales, y en espacial de la salud, respecto a los alcances de la expansión del bienestar, y diversos estudios señalan que el Estado durante el peronismo habría sido incapaz de universalizarlo, existe cierto consenso en que el "gobierno logró una mejora en las condiciones de vida de la población y que el ámbito de cobertura de bienestar se incrementó notablemente, logrando una mayor 'democratización del bienestar" (Hirschegger 2010).

Otro caso relevante es el de la actuación del MNR durante la Revolución Nacional Boliviana. El MNR no solamente benefició al campesinado a través de la reforma agraria, la expansión de los derechos políticos y la eliminación de ciertas formas de trabajo servil. También fomentó la incorporación del campesinado orientando las políticas públicas para hacer viable su inclusión. Esto se notó en la orientación de las obras públicas para mejorar la conectividad de las zonas campesinas aisladas y la expansión del acceso a la educación básica para el campesinado (Mansilla 1980).

Teniendo en cuenta estos antecedentes, nos mostramos en desacuerdo tanto con las visiones que plantean que los movimientos nacional-populares tendrían una naturaleza antidemocrática, como con las que sostienen que estos tipos de movimientos y regímenes podrían clasificarse, de manera dicotómica, entre "democráticos y autoritarios" (Dix 1985: 29-52) . Ante estas visiones, planteamos que los movimientos nacional populares tuvieron un carácter democrático, pero al mismo tiempo antiliberal.

6 Para un análisis del populismo en cuanto ideología "antidemocrática", véase el texto de Salmorán Villar (2017: 127-154), Esta visión subyace en diversos textos políticos de difusión más recientes. Al respecto, véase el texto de Álvaro Vargas Llosa (2017). 
Dicha situación ayuda a explicar cómo presentaron rasgos democráticos y a la vez autoritarios y mantuvieron una relación conflictuada con formas específicas de democracia, como la democracia liberal.

$\mathrm{Al}$ respecto, consideramos necesario señalar que, al igual que Mudde y Rovira Kaltwasser (2012: 10-11), utilizaremos en el análisis una noción mínima de democracia. Siguiendo a dichos autores, entenderemos la democracia de manera procedimental, como un "método" para "elegir gobernantes", a través de "elecciones competitivas". Sus elementos distintivos serían las elecciones competitivas, el gobierno de mayoría y la soberanía popular. Al plantear dicha definición no negamos que la democracia pueda encontrarse ligada a determinados valores que le confieran un carácter sustantivo, sin embargo, consideramos que estos últimos son contingentes a los diversos tipos de escenarios en que pueda tener lugar un régimen democrático. En este aspecto adherimos a los planteamientos de Leonardo Morlino (2011: 25), quien sostiene que la búsqueda de una definición mínima de democracia se vuelve fundamental en un contexto como en el que tienen lugar las investigaciones actuales, en el cual, dicho "tipo de régimen se ha convertido en el único" que es aceptado y "ya no se desafía como tal". Según dicho autor, las "definiciones procedimentales" serían un "punto de referencia" mínimo, que debería "ser complementado por otras definiciones que se refieren a aspectos sustantivos relevantes para la investigación empírica", atendiendo a realidades contingentes específicas. Por lo demás, "una definición minimalista" sería fundamental "para comprender cuándo un régimen se convierte en democracia o está a punto de hacerlo", dando "cuenta de las complejidades de un período de transición, cuando un régimen ya puede ser democrático en algunos aspectos, pero continúa siendo autoritario en otros".

A nuestro parecer, esta elección conceptual, hace posible dar cuenta de las distintas formas que en diversos momentos y circunstancias ha adquirido la democracia, a la vez que evita adoptar enfoques normativos que definan su objeto de estudio incorporando, como parte de sus características distintivas, elementos provenientes de las aspiraciones valórico-políticas del analista ${ }^{7}$. En esta lógica, consideramos que la "democracia liberal" constituye un tipo específico de democracia. El principal elemento distintivo de este tipo de democracia, según Mudde y Rovira Kaltwasser (2012: 13), sería la "protección de los derechos de las minorías". Consideramos necesario reforzar dicha idea, sosteniendo que

7 Sobre las diversas estrategias metodológicas para conceptualizar la noción de democracia, y los debates generados en torno a ellas, véase Collier y Levistky (1997: 430-451). 
la democracia liberal se inscribe en el principio de defensa constitucional de los derechos individuales, incluso ante la voluntad mayoritaria. En este sentido, la asociación del procedimiento democrático a los principios del constitucionalismo liberal es fundamental para comprender su génesis y características (Zakaria 1997).

Siguiendo esta definición mínima, procederemos a explicar, de acuerdo a los criterios expuestos al inicio de esta sección, el por qué los movimientos nacional-populares podrían, ser considerados democráticos. Luego analizaremos las características específicas del tipo de democracia que promovieron, las que podríamos considerar como antiliberales.

Con respecto al uso de mecanismos eleccionarios para legitimar su autoridad, cabe mencionar que, a diferencia de diversas manifestaciones del nacionalismo autoritario y filofascista de entreguerras, que habían evidenciado un rechazo doctrinario a la democracia en cuanto procedimiento de elección de autoridades, los movimientos nacional-populares recurrieron a los procesos electorales para legitimar su autoridad (Bohoslavsky 2017). Por lo demás, les dieron continuidad en el tiempo comprendiendo que debían desenvolverse al interior de un régimen democrático, "aceptándolo como necesario o deseable para la vida política" y planteando que "la competencia electoral" debía ser "el camino para imponer la voluntad popular y no un mero ejercicio de retórica y demagogia, como habían voceado en los ańos las voces del nacionalismo autoritario" (Bohoslavsky 2017). En efecto, si bien movimientos como el MNR y el peronismo tuvieron en sus orígenes vinculaciones con regímenes dictatoriales, como fueron la dictadura de Villarroel y el Gobierno de la Revolución de Junio, ambos entre 1943 y 1946; llegaron al poder a través de elecciones, respectivamente entre 1946 y 1951, y se movilizaron en contra de regímenes precedentes que habían restringido la participación democrática, excluido fuerzas políticas masivas y recurrido al uso de mecanismos electorales fraudulentos o soluciones pretorianas para conseguir dicho objetivos. Por lo demás, dieron continuidad a las elecciones durante sus gobiernos, evidenciando que su relación con los procedimientos democráticos no era meramente instrumental (Torre 2012, Dunkerley 1984).

En relación al énfasis que los movimientos nacionales pusieron en las mayorías y en la voluntad popular, cabe destacar que este se encuentra presente en sus discursos y formulaciones programáticas constituyendo uno de los núcleos fundamentales de su ideología. Este es un rasgo que los movimientos nacional-populares, como forma histórica específica y concreta, comparten con los demás tipos de populismo. Dicha situación responde al contexto al que emergieron como respuesta. En efecto, como 
ha sostenido Carlos de la Torre (2003: 64) el populismo está vinculado con el "modo en que se incorporó la gente común como 'el pueblo', que es diferente y está en oposición a 'la oligarquía”'. De este modo, la centralidad dada a la postura de las mayorías frente a una minoría oligárquica se torna radical en ellos.

En cuanto a la labor de incorporación política y ciudadanización de la población emprendida por los movimientos nacional-populares, debemos señalar que esta se expresó tanto legal como simbólicamente. Legalmente, se evidenció en la expansión de derechos civiles y políticos a la vez que sociales, hacia amplios sectores de la población, los que hasta el momento se habían encontrado marginados o habían accedido a ellos con limitaciones. Con respecto a la expansión de derechos civiles, cabe mencionar el fin de las formas tradicionales de trabajo servil que tuvo lugar en Bolivia bajo el MNR. En el caso de los derechos políticos, ambos movimientos, al llegar al poder implementaron reformas que incorporaron al cuerpo electoral a sectores hasta el momento postergados, fue el caso de las reformas electorales del peronismo, a través de las provincializaciones y el sufragio femenino (Ajmechet 2012), y el establecimiento del sufragio universal y el reconocimiento del voto de los analfabetos durante la Revolución Nacional Boliviana (Lazarte 2007).

Simbólicamente, el proceso de incorporación se hizo notar en la aceptación y exaltación de formas culturales provenientes de los sectores populares, que anteriormente habían tendido a ser negadas o relegadas a un segundo plano por los sectores dominantes. Dicho aspecto se convirtió en el correlato cultural de la irrupción en la política de actores sociales postergados al legitimar sus características y su presencia en el espacio público. Este punto ha sido sintetizado por Mackinnon y Petrone (1999) quienes, refiriéndose a los "populismos clásicos", han sostenido que su "dimensión fundamental” sería su:

Capacidad de incorporación no solamente en el nivel social (a través de la legislación, de los derechos sociales) sino también en el nivel político (a través de la institucionalización de la participación política por parte del Estado) y en el plano simbólico (a través de la noción de pueblo y el nacionalismo) de una amplia franja de sectores excluidos en los regímenes anteriores.

Reforzando este punto, Carlos de la Torre (2013), ha sostenido que:

El populismo entendió la democracia como la ocupación de espacios públicos de los cuales los pobres y los no blancos estaban excluidos, 
más que como el respeto a las normas e instituciones de la democracia liberal [...] La ocupación de espacios a través de marchas, mítines políticos y asambleas se ha dado junto con discursos maniqueos a favor del pueblo, construido como la encarnación de las virtudes y los valores "auténticos" de la nación, y en contra de la oligarquía "corrupta y vendepatria".

Pese a su carácter democrático y su tendencia explicita a promover la incorporación de sectores subalternos que tradicionalmente habían sido postergados, un elemento que distinguirá a los movimientos nacional populares es su carácter antiliberal. Esto puede explicarse, en parte por el contexto ideológico y sociopolítico en que emergieron, como por la tensa y compleja relación que han tenido con el pluralismo político. No es de extrañar que incluso las políticas de incorporación de los sectores populares hayan sido miradas desde una lógica antioligárquica y antiliberal. Así, en el marco de las reformas constitucionales discutidas en 1949 en Argentina, el peronismo mostró a los derechos sociales como propios de una nueva realidad, que se opondría al anterior orden de cosas de carácter oligárquico y liberal (Martínez Mazzola 2012).

Para entender su tendencia reactiva y su relación conflictuada con el liberalismo político, en primera instancia, se vuelve necesario hacer referencia al momento histórico en que dichos movimientos emergieron, dando cuenta del ambiente ideológico-intelectual y de las condiciones sociopolíticas que marcaron sus características. Gino Germani (1973: 24-25) ha planteado que, a diferencia del siglo XIX, en el siglo XX, y especialmente tras la primera guerra mundial, la "democracia liberal" habría dejado de ser "conceptuada como un modelo de modernización", como en el "pasado". A contrario sensu, esta habría pasado a ser considerada como una ideología conservadora, con tendencias a proteger la estructura tradicional de los países dependientes". Torcuato Di Tella (1973: 44) ha planteado un argumento similar, al señalar que, en el "período histórico" en que emergió el fenómeno, el liberalismo ya no sería una "ideología antistatu quo", por el contrario, estaría mezclado con la ideología de las clases dominantes de las potencias del mundo occidental" y, por ende, aparecería como "contaminado", por "el imperialismo y por grupos locales ligados a intereses extranjeros". Así, algunas corrientes reformistas y antioligárquicas tendieron a alejarse del liberalismo, tendencia que se vio facilitada por la circulación y transferencia de ideas nacionalistas antiliberales provenientes, principalmente desde Europa en el período de entreguerras, y desde el tercer mundo en la postguerra. No es de extrañar que los movimientos nacional populares se nutrieran de manera ecléctica de doctrinas y modelos que tenían, como rasgo común, su antiliberalismo. Basta mencionar como 
ejemplo, en el caso de la oficialidad argentina desde donde emergió Perón en la década de 1940, la recepción de elementos ideológicos provenientes de la Italia de Musolinni y del socialcristianismo en sus variantes corporativistaautoritarias e hispanistas (Zanatta 1999). También puede hacerse alusión al influjo ejercido por el nacional socialismo alemán y el fascismo italiano entre algunos de los fundadores del MNR boliviano (Koehler, Marconatto y Silva 2007).

Sin embargo, el elemento fundamental para explicar el carácter antiliberal de los movimientos nacional-populares es, la conflictiva relación que estos han tenido con el pluralismo político. Dichas dificultades se derivan del modo en que, en general, los populismos conciben al "pueblo". Según Laclau, para el populismo el "pueblo" sería "algo menos que la totalidad de los miembros de una comunidad", siendo "un componente parcial que aspira, sin embargo, a ser concebido como la única totalidad legítima”. Haciendo una analogía con la república romana, el autor sostiene que sería necesaria la existencia de "una plebe que reclame ser el único pópulus legítimo - es decir una parcialidad que quiera funcionar como la totalidad de la comunidad" (Laclau 2007: 108). Desde una mirada ideológica opuesta a la de Laclau, pero llegando a conclusiones similares Marc Plattner (2010: 88), ha sostenido que "el populismo encarna una visión de la democracia que no está ligada al liberalismo o al constitucionalismo" y que, si bien este "sigue siendo democrático en el sentido mayoritario", al justificarse "a sí mismo como el agente y la encarnación del pueblo como un todo" excluye" a la élite corrupta y privilegiada y sus agentes". Así, quienes difieran de "el pueblo" en cuanto "grupo uniforme", pasarían a ser "considerados como enemigos". De este modo, para Plattner (2010: 90), el "populismo" y el "pluralismo radical, serían fuerzas anatgónicas.

Rovira y Mudde (2012: 17) también han profundizado en este punto al plantear que:

Como una ideología esencialmente monista que cree en la existencia de una "voluntad general del pueblo", el populismo es hostil hacia el pluralismo y la protección de las minorías. En consecuencia, el populismo se basa en la primacía de lo político, lo que significa que cualquier otro centro institucional de poder, incluido el judicial, se considera secundario.

Tras dar cuenta de la dicotomía existente entre populismo y pluralismo radical, es relevante hacer ciertas matizaciones que nos permiten distinguir a los populismos de ideologías que promueven autoritarismos radicales. Es necesario resaltar que el populismo asigna al pluralismo un rol secundario 
y que tiene una relación tensa con este, en cuanto se le opone, pero no lo anula completamente. En efecto, la aceptación de la legitimidad del procedimiento democrático por parte de los movimientos populistas, implica que, una vez en el poder mantengan procesos electorales que ofrezcan cierto grado de competitividad, sin anular completamente las posibilidades de la oposición. Este punto se relaciona directamente con el carácter dual de los populismos, el que, si bien destaca el antagonismo hacia un sector de la sociedad, aspira a la vez la representación completa de esta, tolerando ciertos niveles de pluralismo. Gerardo Aboy Carlés (2003: 2), discutiendo con la visión absoultamente dicotómica que planteó Ernesto Laclau, especialmente en sus últimas obras, ha sintetizado este último punto al señalar:

La coexistencia en el populismo de dos tendencias contradictorias como son la constitución de una ruptura fundacional en la que el pueblo se constituye antagónicamente respecto del bloque de poder $y$, por lo tanto, privilegiando una exclusión radical en el seno de la comunidad política, y por otra parte, la pretensión hegemonista de representar a la comunidad como un todo.

En el caso de los movimientos nacional-populares, estas características se notan en su tendencia a hostigar y reprimir a sectores políticos opositores o a disidentes en las propias filas, violentando garantías mínimas del constitucionalismo liberal, pero sin eliminar o proscribir completamente su presencia. En este sentido, autores como Carlos de la Torre (2013) han sostenido que los populismos generarían "democracias delegativas", las que, si bien respetan la regla de mayoría, asumen el triunfo como un mandato total sin contrapesos posibles por parte de los perdedores y minorías. En el período que estudiamos, los gobiernos de Víctor Paz Estenssoro, entre los años 1952-1956 y 1960-1964, habrían tenido una lógica represiva hacia sectores disidentes, llegando a ser descritos, como es el caso de la obra de Thomas C. Field (2016), como un caso de "desarrollismo autoritario", en cuanto habría promovido políticas de desarrollo estructuralista a la vez que habría mantenido una fuerte represión especialmente de carácter anticomunista. Estas características se marcan de manera evidente en el caso argentino, con los continuos hostigamientos a los opositores, clausuras de diarios o requisición de sedes. También se evidencian en la persecución que recibió a disidencia sindical. Sin embargo, en ambos casos los partidos disidentes tuvieron permitido presentarse a elecciones y pudieron mantener sus organizaciones sin ser ilegalizados (Torre 1998).

Vinculado al punto anterior, es necesario reparar en otro tópico, como es el de la relación de los movimientos nacional-populares con 
las instituciones. Al respecto, diversas investigaciones han tendido a resaltar el carácter antiinstitucional que, en general, habrían tenido los populismos, incluyendo en ellos a los "populismos clásicos", asimilables a los movimientos nacional-populares que estamos analizando. Como habíamos planteado en la primera sección de este apartado, autores que han estudiado los populismos desde un enfoque institucionalista, han insistido en la falta de institucionalización como el factor fundamental

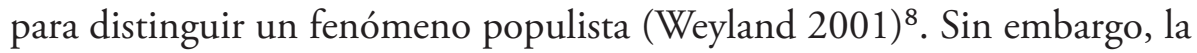
evidencia que nos entregan los movimientos nacional-populares nos lleva a diferir de dicha hipótesis. Al analizar la organización de los movimientos nacional populares, diversos autores han señalado como estos desarrollaron importantes grados de institucionalización, tanto en el ámbito político partidista, como su relación con los sindicatos (Mackinnon 2000, Torre 2012). De hecho, la impronta del corporativismo se hizo sentir en diversas bases de apoyo política e intelectual que dieron su apoyo a la emergencia del liderazgo de Perón y al ascenso del ibañismo en Chile durante la década de 1920 (Gomes 2016), dichos sectores, si bien tenían un carácter antiliberal, ponían espacial énfasis en una agenda de transformación institucional. Del mismo modo, un análisis de la actuación de dichos movimientos cuando han llegado al gobierno señala la importancia que dieron a la reforma constitucional, a la creación de nuevas agencias estatales y a la transformación en derechos de determinados beneficios sociales. Las prácticas políticas recién mencionadas se inscriben en una clara lógica institucionalista. Esto nos lleva a coincidir con la crítica planteada por, Gerardo Aboy Carlés (2010: 26), quién ha sostenido que:

[...] los diferentes ensayos constitucionales llevados a cabo por diversas experiencias populistas [...], muchas veces no aprobados por diversos sectores, pero aceptados al concurrir a elecciones bajo su imperio, demostrarían por si solos la fragilidad del argumento de una mutua exclusión de populismo e institucionalismo".

Si bien discrepamos de los esquemas que analizan a los populismos como antiinstitucionalistas, consideramos que importantes elementos de su crítica son pertinentes al análisis y deben llevar a que los investigadores tematicen la complejidad en las relaciones entre populismos e instituciones. Esto pues el énfasis en la voluntad popular, en el principio de unanimidad y la movilización social por sobre las garantías individuales del constitucionalismo liberal que exhiben los populismos, implican necesariamente la existencia de grados variables de arbitrariedad que se

8 Un ejemplo claro de esta línea teórica es el artículo de Patricio Navia (2003), quien define el populismo como "un esfuerzo por debilitar las instituciones". 
contradicen con una lógica institucionalista. Al respecto, consideramos necesario rescatar reflexiones que se han desarrollado recientemente, como las de Claudio Riveros (2018) Pierre Ostiguy (2014).

Riveros (2018) sostiene la necesidad de alejarse del "argumento que plantea una oposición insalvable entre populismo e institucionalismo". En este sentido, Pierre Ostiguy ha desarrollado el concepto de "institucionalidad sucia". El autor plantea que "dicha "institucionalidad sucia" se contrapone a la "institucionalidad prolija" que anhelan los institucionalistas "republicanos', que en realidad son institucionalistas liberales en el mejor sentido político y filosófico del adjetivo” (Ostiguy 2014: 364). La institucionalidad sucia se caracterizaría por la utilización de "métodos y prácticas discursivas y simbólicas que no son "políticamente correctos"' y que estarían permeados por elementos que culturalmente provienen de sectores subalternos. Según Riveros (2017: 79), dicho esquema ayudaría a superar la diferenciación tajante entre institucionalización y movilización. También consideramos que el potencial de análisis del concepto puede ser ampliado. Esto pues, a nuestro juicio, permite evitar la dicotomía absoluta entre autoritarismo mayoritario e institucionalidad permitiendo entender la actuación de movimientos que promueven la formación de instituciones, y que a la vez pueden soslayarlas o transformarlas cuando entran en conflicto con sus aspiraciones y se perciben como contradictorias con la voluntad mayoritaria. De esta manera, las relaciones entre los movimientos nacional-populares y las instituciones se mantienen en una constante tensión, retroalimentándose en algunas ocasiones y entrando en conflicto en otras, pero en ningún caso entrando en una contradicción absoluta.

También consideramos necesario detenernos en otro aspecto vinculado a este punto, como es el de la relación entre los movimientos nacionalpopulares y las formas personalistas de liderazgo. Al respecto, se vuelve relevante señalar que dicho punto se ha encontrado presente en diversas definiciones de populismo y que incluso ha llegado a ser seńalado por algunos autores como un elemento central y constitutivo del fenómeno. Esta tendencia se hace patente, de manera especial en los enfoques "relacionales" e "institucionalistas", situación que no es de extrañar, en cuanto los liderazgos personalistas y el carisma se vuelven variables fundamentales en abordajes teóricos que enfatizan en los "estilos políticos" (Conniff 1999) o consideran que la emergencia del populismo se relaciona con la debilidad de instituciones (Weyland 2001, Navia 2003). Sin embargo, algunos autores vinculados a enfoques clásicos en los estudios sobre el populismo,

9 El autor utiliza el término inglés propper. 
como las teorías de la modernización o el dependentismo, también dieron primacía en el análisis a este factor. Para los primeros, la tendencia al personalismo sería una consecuencia del carácter "tradicional" de las masas movilizadas, acostumbradas aún a vínculos adscritos y ajenas a las formas de autoridad y liderazgo impersonal de la modernidad (Germani 1973), mientras que, para los segundos, el líder carismático ejercería el rol de articulador entre un conjunto de fuerzas sociales con intereses disímiles entre sí (Weffort 1967). En Latinoamérica, durante el período que estudiamos, la emergencia de dirigentes políticos caudillistas, cuyo liderazgo respondía a muchas de las características que se atribuyen a las formas de autoridad carismáticas (Weber 2014), reforzó la hegemonía de dicha interpretación. Sin embargo, consideramos que dicho punto debe ser matizado. En primer lugar, pues coincidimos con autores que señalan que, en este punto, muchos analistas estudian Latinoamérica según estándares de impersonalidad en los liderazgos políticos que difícilmente se cumplen, incluso en Europa (Knight 1998). Al respecto, basta pensar en casos como el del Gaullismo en la Francia de postguerra (Riquelme 2008). De la misma manera, dicha visión no atiende la diversidad de los movimientos nacional populares en el período. Si bien una de las características centrales del peronismo en Argentina y del varguismo en Brasil, fue la dependencia del líder; dicha situación no fue tan evidente en circunstancias como la del aprismo peruano. Si bien el personalismo de Victor Raúl Haya de la Torre jugó un importante papel en dicho partido, su estructura no se definió nunca en términos personalistas, contando con organizaciones sólidas y altamente institucionalizadas (Cotler 1996). Dicha situación se vuelve aún más marcada en el caso del Movimiento Nacionalista Revolucionario Boliviano. En definitiva, si bien la tendencia al caudillismo y el personalismo está presente en varios movimientos nacional populares, no es un rasgo necesariamente definitorio de estos ni que se encuentre presente en todos ellos.

\section{REFLEXIONES FINALES}

Se vuelve necesario señalar la imposibilidad de asociar al populismo a un tipo específico de política pública. Ciertos elementos generales del populismo, como la exaltación de lo "popular" o una predisposición antielitista pueden marcar algunas características de las políticas públicas asociadas a regímenes o gobiernos populistas. Sin embargo, la variedad de gobiernos y regímenes que han tenido características populistas vuelve imposible distinguir en ellos un patrón común de política pública. Por lo demás, los elementos antioligárquicos o pro-populares que puedan existir en determinadas políticas públicas no necesariamente marcan la tónica completa del movimiento o partido que las defiende ni del gobierno o 
régimen en que devino al llegar a poder. En este aspecto, el uso del término populismo para categorizar determinadas políticas públicas, refuerza la tendencia a vulgarizar el concepto y convertirlo en un epíteto denostativo, restándole valor analítico. Del mismo modo, coadyuva a confundir políticas coyunturales con tónicas generales.

Dada la hegemonía que han adquirido en el debate público y su capacidad de instalarse en los escenarios académicos, se vuelve especialmente necesario discutir las tesis monetaristas ortodoxas que han asociado el concepto de populismo al de las políticas públicas destinadas a la satisfacción inmediata de demandas sociales, políticas fiscales expansivas y el relegamiento de las variables monetarias y equilibrios macroeconómicos a un rol secundario. Esto pues dicho tipo de medidas han sido aplicadas incluso por regímenes que actuaron como frenos a gobiernos tildados de populistas. Este fue el caso de las dictaduras militares del cono sur desde mediados de la década de 1960, las que, pese a su agenda económica general, en determinados momentos aplicaron políticas de alto gasto fiscal y buscaron apoyos a través del uso de estas en la satisfacción de demandas inmediatas. Por lo demás, en determinados momentos históricos, como fue el caso del período comprendido entre la crisis de 1929 y la década de 1970, muchas de las características atribuidas al populismo por esta corriente interpretativa, fueron parte de un consenso y sentido común en el modo de entender las políticas económicas y sociales, marcadas especialmente por la hegemonía del keynesiamo y el crecimiento del Estado de Seguridad Social. Así, el riesgo de transformar al populismo en un concepto total, que da cuenta de una época antes que de fenómenos específicos, lo debilitan como categoría analítica.

A diferencia del concepto general de populismo, en el caso específico de los movimientos nacional populares, en cuanto un tipo específico y forma concreta de populismo, si podemos vincularlos con ciertos tipos específicos de políticas. Esto se debe a la naturaleza histórica más acotada y de alcance medio que posee el concepto. Características como el nacionalismo esencialista, la reivindicación de las demandas sociales y los elementos culturales atribuidos a los sectores populares y la exaltación del principio de soberanía nacional, marcaron las políticas públicas de los movimientos nacional-populares.

Las políticas de los movimientos nacional-populares promovieron procesos de democratización e integración, a la vez que reforzaron el poder de los gobernantes, debilitando el pluralismo y la capacidad de acción de eventuales sectores disidentes. Sin embargo, no consideramos correcto plantear que estas políticas necesariamente debilitaron las instituciones 
o reforzaron liderazgos personalistas, como han sostenido algunas interpretaciones institucionalistas del populismo. No todos los movimientos nacional-populares administraron sus políticas de manera personalista y todos, de distintas maneras, generaron instituciones quereforzaron los procesos de democratización e impulsaron las políticas económicas y de seguridad social. En este sentido, caudillismo y antiinstitucionalismo no fueron características compartidas por los movimientos nacional populares $y$, por lo mismo, no pueden ser considerados como factores clave para distinguir casos de populismo.

Con todo, consideramos necesario enfatizar en el carácter nacionalistaantioligárquico, a la vez que democrático y antiliberal los movimientos nacional-populares, con el fin de rescatar su especificidad y distinguirlos de otros tipos de movimientos políticos antioligárquicos y promotores de la participación política de los sectores populares en el período. 


\section{REFERENCIAS}

Aboy Carlés, G. (2003). Repensando el Populismo. Politica y Gestión, 4, 9-34.

. (2010). Las Dos Caras de Jano: Acerca de la Compleja Relación entre Populismo e Instituciones Políticas. Pensamiento Plural, Pelotas, 7, 21-40.

Adamovsky, E. (2015). ¿De Qué Hablamos Cuando Hablamos de Populismo? Revista Anfibia. Disponible en http://revistaanfibia.com/ ensayo/de-que-hablamos-cuando-hablamos-de-populismo-2/ [15-122018].

Ajmechet, S. (2012). El Peronismo como Momentos de Reformas (19461955). Revista SAAP, 6 (2), 249-266.

Bavili, N. (2017). Policy Making in Populist Context. Open Journal of Political Science, 7, 432-439.

Bergel, M. (2009). Nomadismo Proselitista y Revolución. Notas para una Caracterización del Primer Exilio Aprista (1923-1931). EIAL: Estudios Interdisciplinarios de America Latina y el Caribe, 20 (1), 41-66.

Bohoslavsky, E. (2017). Nacionalismos Autoritarios y Nacionalismos Populistas: Cercanías y Distancias en Sudamérica. En Donatello, L., Mallimaci, F. y Pinto, J. (Eds.), Nacionalismos, religiones y globalización. Buenos Aires: Biblos.

Breully, J. (1982). Nationalism and the State. Manchester: Manchester University Press.

Cancino, H. (2012). La Reemergencia del Discurso Nacional-Popular en la Nueva Izquierda Latinoamericana. Para una Discusión de los Movimientos Nacional Populares. Diálogos Latinoamericanos, 13, $27-$ 43.

Canovan, M. (1981). Populism. Nueva York: Hartcourt Brace Jovanocich. . (1993). Trust the People! Populism and the Two Faces of Democracy. Political Studies, 47 (1), 2-16. 
Carey, J. (1992). The Intellectuals and the Masses'... 'Pride and Prejudice among the Literary Intelligentsia 1880-1939. Londres: Faber and Faber.

Collier, D. y Mahon, J. E. (1993). Conceptual 'Stretching' Revisited: Adapting Categories in Comparative Analysis. American Political Science Review, 87(4), 845-855.

Collier, D. y Levitsky, S. (1997). Democracy with Adjectives: Conceptual Innovation in Comparative. Research. World Politics, 49 (3), 430-451.

Conniff, M. (1999). Populism in Latinamerica. Tuscaloosa: University of Alabama Press.

(2003). Neopopulismo en América Latina: La Década de los 90 y Después. Revista de Ciencia Política, 23 (1), 31-38.

Cortés, A. y Pelfini A. (2017). El Populismo en Chile: ¿Tan Lejos o Tan Cerca? Izquierdas, 32, 58-78.

Cotler, J. (1996). Partidos Políticos y Problemas de Consolidación Democrática en el Perú. En Mainwaring, S. (Ed.), La Construcción de Instituciones Democráticas: Sistema de Partidos en América Latina. Santiago: CIEPLAN.

De La Torre, C. (2003). Masas, Pueblo y Democracia: Un Balance Crítico de los Debates sobre el Nuevo Populismo. Revista de Ciencia Política, XXXIII (1), 55-66.

(2013). El Populismo Latinoamericano. Entre la Modernización y el Autoritarismo. Nueva Sociedad, 247, 121-137.

Deiwiks, C. (2009). Populism. Living Reviews in Democracy, 1, 1-9

Diani, M. (1996). Linking Mobilization Frames and Political Opportunities: Insights from Regional Populism in Italy. American Sociological Review, 61 (6), 1053-1069.

Di Tella, T. (1973). Populismo y Reformismo. En Germani, G, Di Tella, T. e Ianni, O. (Eds.), Populismo y Contradicciones de Clase en Latinoamérica. México: Ediciones Era.

Dix, R. (1985). Populism: Authoritarian and Democratic. Latin American Research Review, 20 (2), 29-52. 
Dornbusch, R. y Edwards, S. (1989). Macroeconomic Populism in Latin America. NBER Working Paper No. 2986.

Dunkerley, J. (1984). Rebellion in the Veins. Political Struggle in Bolivia, 1952-1982. Londres: Verso.

Edwards, S. y Dornbush, R. (1991). The Macroeconomics of Populism in Latin America. Chicago: University of Chicago Press.

Faletto, E. y Cardoso, F. (1969). Dependencia y Desarrollo en América Latina. Buenos Aires: Siglo XXI.

Fekete, L. (2016). Hungary: Power, Punishment and the 'ChristianNational Idea.' Race \& Class, 57 (4), 39-53.

Field, T. C. (2016). Minas, Balas Y Gringos. Bolivia y la Alianza para el Progreso en la Era de Kennedy. La Paz: CIS.

Germani, G. (1965). Politica y Sociedad en una Época De Transición: De la Sociedad Tradicional a la Sociedad de Masas. Buenos Aires: Paidós.

. (1973). Democracia Representativa y Clases Populares En Germani, G, Di Tella, T. e Ianni, O. (Eds.), Populismo y Contradicciones de Clase en Latinoamérica. México: Ediciones Era.

Gomes, G. (2016). La Opción Corporativista en Argentina y Chile: Agrupaciones Políticas y Círculos Intelectuales (1930-1970). Amérique Latine Histoire et Mémoire. Les Cahiers ALHIM, 32.

Hirschegger, I. (2010). El Bienestar Social Durante el Peronismo Clásico: La Expansión de los Servicios de Salud hacia las Áreas Rurales de los Municipios de la Provincia de Mendoza (1946-1955). Mundo Agrario, $11(21)$.

Hobsbawm. E. (1983). Introduction: Inventing Traditions. Hobsbawm. E y Ranger, T. (Eds.), The invention of Tradition. Cambridge: Cambridge University Press.

Hutchinson, J. (1987). The Dynamics of Cultural Nationalism. Londres: Allen and Unwin.

Ianni, O. (1973). Populismo y Relaciones de Clase en Latinoamérica. En Germani, G, Di Tella, T. e Ianni, O. (Eds.), Populismo y Contradicciones 
de Clase en Latinoamérica. México: Ediciones Era.

Iglesias, P. (2016). Trump y el Momento Populista. Público. Disponible en http://blogs.publico.es/pablo-iglesias/1091/trump-y-el-momentopopulista/ [15-12-2018].

Ingram, J. (2017). Populism and Cosmopolitanism. En Rovira Kaltwasser, C., Taggart, P., Ochoa Espejo, P. y Ostiguy, P. (Eds.), The Oxford Handbook of Populism. Oxford: Oxford University Press.

James, D. (2010). Resistencia e Integración: El Peronismo y la Clase Trabajadora Argentina, 1946-1976. Buenos Aires: Siglo Veintiuno.

Kaiser, A. y Álvarez, G. (2016). El Engaño Populista: Por Qué Se Arruinan Nuestros Países y Cómo Rescatarlos. Madrid: Deusto.

Kantor, H. (1966). The Ideology and Program of the Peruvian Aprista Movement. Nueva York: Octagon Books.

Knight A. (1998). Populism and Neo-Populism in Latin America, Especially Mexico. Journal of Latin American Studies, 30, 223-248.

Koehler, C. R., Marconatto, P. y Silva, R. (2007). Bolivia en el Péndulo de la Historia. Nueva Sociedad, 209, 130-141.

Lacalu, E. y Mouffe, C. (1987). Hegemonía y Estrategia Socialista. Hacia una Radicalización de la Democracia. Madrid: Siglo XXI.

Laclau, E. (1996). ¿Por Qué los Significantes Vacíos Son Importantes para la Política? En Laclau, E. (Ed.), Emancipación y Diferencia. Buenos Aires: Ariel.

Cultura Económica.

- (2007). La Razón Populista. Buenos Aires, Fondo de

Lazarte, J. (2007). Reforma Electoral en Bolivia. En Zovatto, D. y Orozco Henriquez, J. (Comp.), Reforma Politica y Electoral en América Latina, 1978-2007. México: Universidad Autónoma de México.

Löwy, M. (1989). Transformación del Populismo en América Latina. Utopias del Sur, II (3), 5-15. 
Mackinnon, M. M. (2002). Los Años Formativos del Partido Peronista (1946-1950). Buenos Aires: Siglo Veintiuno.

Mackinon M. M. y Petrone M. A. (1999). Introducción: Los Complejos de la Cenicienta. En Mackinon M. M. y Petrone M. A. (Eds.), Populismo y Neopopulismo en América Latina. El Problema de la Cenicienta. Buenos Aires: Eudeba.

MacRae, D. (1969). Populism as an Ideology. En Ionescu, G. y Gellner, E. (Eds.). Populism: Its Meanings and National Characteristics. Londres: Weinfeld and Nicholson.

Mansilla, H. C. F. (1980). La Revolución de 1952 en Bolivia: Un Intento Reformista de Modernización. Revista de Estudios Politicos, 17, 117128.

Martínez Mazzola, R. (2012). ¿Herederos de Mayo y la Constitución de 1853? Liberalismo y Antiliberalismo en el Debate sobre la Reforma Constitucional de 1949. Apuntes de Investigación del CECYP, 21, 77105.

Merton, R. (1968). Social Theory and Social Structure. Nueva York: The Free Press.

Montero. A. D. (2012). Significantes Vacíos y Disputas por el Sentido en el Discurso Político: Un Enfoque Argumentativo. Identidades, 3 (2), $1-25$.

Morlino, L. (2011). Changes for Democracy: Actors, Structures, Processes. Oxford: Oxford University Press.

Mudde, C. y Rovira Kaltwasser, C. (2012). Populism and (Liberal) Democracy: A Framework for Analysis. En Mudde, C. y Rovira Kaltwasser, C. (Eds.), Populism in Europe and the Americas: Threat or Corrective for Democracy. Cambridge: Cambridge University Press.

. (2013). Populism. En Rovira Kaltwasser, C., Taggart, P., Ochoa Espejo, P. y Ostiguy, P. (Eds.), The Oxford Handbook of Populism. Oxford: Oxford University Press.

Mudde. C. (2017). Populism: An Ideational Approach. En Rovira Kaltwasser, C., Taggart, P., Ochoa Espejo, P. y Ostiguy, P. (Eds.), The Oxford Handbook of Populism. Oxford: Oxford University Press. 
Navia, P. (2003) Partidos Políticos como Antídoto contra el Populismo en América Latina. Revista de Ciencia Política (Santiago), XXIII (1), 19-30.

Ostiguy, P. (2009). The High and The Low in Politics: A Two-Dimensional Political Space for Comparative Analysis and Electoral Studies. Working Paper \# 360. The Kellog Institute.

. (2014). Exceso, Representación y Fronteras Cruzables: "Institucionalidad Sucia" o la Aporía del Populismo en el Poder. Postdata, 19 (2), 345-375.

. (2017). Populism: A Sociocultural Approach. En Rovira Kaltwasser, C., Taggart, P., Ochoa Espejo, P. y Ostiguy, P. (Eds.), The Oxford Handbook of Populism. Oxford: Oxford University Press.

Plattner, M. (2010). Populism, Pluralism, and Liberal Democracy. The Journal of Democracy, 21 (1), 81-92.

Pontón Cevallos, J. (2016). El Populismo: ¿Una Amenaza a la Democracia en América Latina? Un Diálogo con Kurt Weyland. Íconos. Revista de Ciencias Sociales, 55, 163-168.

Portantiero, J. C. (1991) Gramsci en Clave Latinoamericana. Nueva Sociedad, 115, 152-157.

Portantiero, J. C. y De Ipola, E. (1981) Lo Nacional Popular y los Populismos Realmente Existentes. Nueva Sociedad. 54, 1. 7-18.

Reveco. J. M. (1992). Un Repaso a las Teorías sobre el Populismo Latinoamericano. Estudios Sociales, 73, 31-46.

Riquelme, A. (2008). Joaquín Fernández Abara, El Ibañismo (19371952): Un Caso De Populismo en la Política Chilena. Historia 41 (1), 233-236.

Riveros, C. (2018). El Proceso Populista: Un Aporte Teórico al Debate del Fenómeno. Izquierdas, 38, 61-88.

Roberts, K. (1995). Neoliberalism and the Transformation of Populism in Latin-America: The Peruvian Case. World Politics, 48 (1), 82-116. 
Rovira Kaltwasser, C. Y Hawkins, K. (2017). The Ideational Approach to Populism. Latin American Research Review, 52 (4), 513-528.

Roxborough, I. (1984). Unity and Diversity in Latin American History. Journal of Latin American Studies, 16 (1), 1-26.

Sachs, J. D. (1989). Social Conflict and Populist Policies in Latin America. NBER Working Paper No. 2986.

Salmorán Villar, M. G. (2017). Populismo: Una Ideología Antidemocrática. Teoria Politica, 7, 127-154.

Torre, J. C. (2012). Ensayos sobre Movimiento Obrero y Peronismo. Buenos Aires: Siglo XXI Editores.

Touraine, A. (1989). América Latina. Política y Sociedad. Madrid: Espasa Calpe.

. (1999). Las Políticas Nacional-Populares. En Mackinon M. M. y Petrone M. A. (Eds.), Populismo y Neopopulismo en América Latina. El Problema de la Cenicienta. Buenos Aires: Eudeba.

Riquelme, A.(2008). Joaquín Fernández Abara, El Ibañismo (1937-1952): Un Caso de Populismo en la Política Chilena. Historia, 41 (1), 233236.

Varela Petito, G. (2008). Reseña de "Gino Germani en su Circunstancia" de Gino Germani y Alejandro Blanco. Perfiles Latinoamericanos, 32, 235-243.

Vargas Llosa, A. (2017). El Estallido del Populismo. Madrid: Planeta.

Velásquez Gavilanes, R. (2010) Hacia una Nueva Definición del Concepto "Política Pública". Desafíos, 20, 149-187.

Weber, M. (2014). Economía y Sociedad. México: Fondo de Cultura Económica.

Weffort, F (1967). El Populismo en la Política Brasileña. En Mackinon M. M. y Petrone M. A. (Eds.), Populismo y Neopopulismo en América Latina. El Problema de la Cenicienta. Buenos Aires: Eudeba. 
Weyland, K. (2001). Clarifying a Contested Concept: Populism in the Study of Latin American Politics. Comparative Politics, 34 (1), 1-22.

Worsley, P. The Concept of Populism. En Ionescu, G. y Gellner, E. (Eds.), Populism: Its Meanings and National Characteristics. Londres: Weinfeld and Nicholson.

Zakaria, F. (1998). The Rise of Illiberal Democracy. Foreign Affairs, 76 (6), $22-43$.

Zanatta, L. (1999). Perón y el Mito de la Nación Católica. Iglesia y Ejército en los Orígenes del Peronismo 1943-1946. Buenos Aires: Editorial Sudamericana.

. (2013). La Internacional Justicialista: Auge y Ocaso de los Sueños Imperiales de Perón. Buenos Aires: Sudamericana.

Recibido: 01-10-2018

Aceptación de la versión final: 20-12-2018 